\title{
LA EMERGENCIA DE LA DIVERSIFICACIÓN DE LA CAZA EN LAS SIERRAS DE TANDILIA ORIENTAL DURANTE EL HOLOCENO TARDÍO FINAL
}

\section{THE EMERGENCE OF THE DIVERSIFICATION OF HUNTING IN THE EASTERN EDGE OF TANDILIA RANGE DURING FINAL LATE HOLOCENE}

\author{
Carlos A. Quintana ${ }^{1}$ y Diana L. Mazzanti ${ }^{2}$ \\ 1 Laboratorio de Arqueología, UNMDP. E-mail: quintanamdp@gmail.com \\ 2 Laboratorio de Arqueología, UNMDP. E-mail: arqueolab@gmail.com
}

Presentado el: 04/04/2014 - Aceptado 04/07/2014

\begin{abstract}
Resumen
Se discute la diversidad de la subsistencia en sitios arqueológicos del Holoceno tardío final de las sierras del sector oriental de Tandilia. A través de las relaciones entre estrategias diferentes de caza, que comprende a presas grandes y a presas pequeñas, se plantea que entre los ca 1000 AP y $700 \mathrm{AP}$ se desarrolló un nuevo modelo de subsistencia para esta área serrana. El mismo consiste en la disminución de la apropiación de presas grandes, el aumento y diversificación de las pequeñas, la aplicación de procesamientos carniceros complejos y la incorporación de vertebrados menores a $1 \mathrm{~kg}$ de masa. Este tipo de subsistencia ocurre en el contexto de asentamientos indígenas de mayor duración, con la presencia de arte rupestre, tejidos, el uso de alfarería, el desarrollo de tecnología lítica y ósea especializada en un contexto de cambio social en cazadores-recolectores prehispánicos.
\end{abstract}

Palabras claves: Tandilia, Holoceno tardío, Diversificación, Intensificación.

Abstract

The diversity of subsistence in late Holocene archaeological sites in the end of the eastern sector of Tandilia range is discussed. Through the relationships between different hunting strategies, comprising a large game and small game, which arises between ca 1000 BP and 700 BP came up with a new model of subsistence for this mountain area. It consists in decreasing the appropriation of large prey, the increase and diversification of small ones, with developing of complex butchers processing and the incorporation of vertebrates lower to $1 \mathrm{~kg}$ of mass. This type of subsistence occurs in the context of 
indigenous settlements of longer duration, the presence of rock art, textiles, pottery use, development of lithic and bone specialized technology in a context of social change in prehispanic foragers.

Keywords: Tandilia range, Last Holocene, Diversification, Intensification.

\section{Introducción}

El registro arqueológico de las sierras de Tandilia oriental (Figura 1) presenta una secuencia en la que están representadas desde las primeras sociedades cazadorasrecolectoras que poblaron esta región, hasta las jefaturas ecuestres de tiempos posconquista (Mazzanti 2007). El análisis de las estrategias de subsistencia muestra el desarrollo de cambios y continuidades en diversos momentos del Holoceno (Quintana y Mazzanti 2001) caracterizados por los tipos de presas capturadas, el contexto arqueológico y las condicionantes ambientales. Este modo dinámico de vincularse con el medio presenta cambios rápidos y profundos en tiempos tardíos, incluso en la apropiación de recursos de las sociedades de contacto hispano-indígena (Mazzanti 2007, Mazzanti y Quintana 2010a).

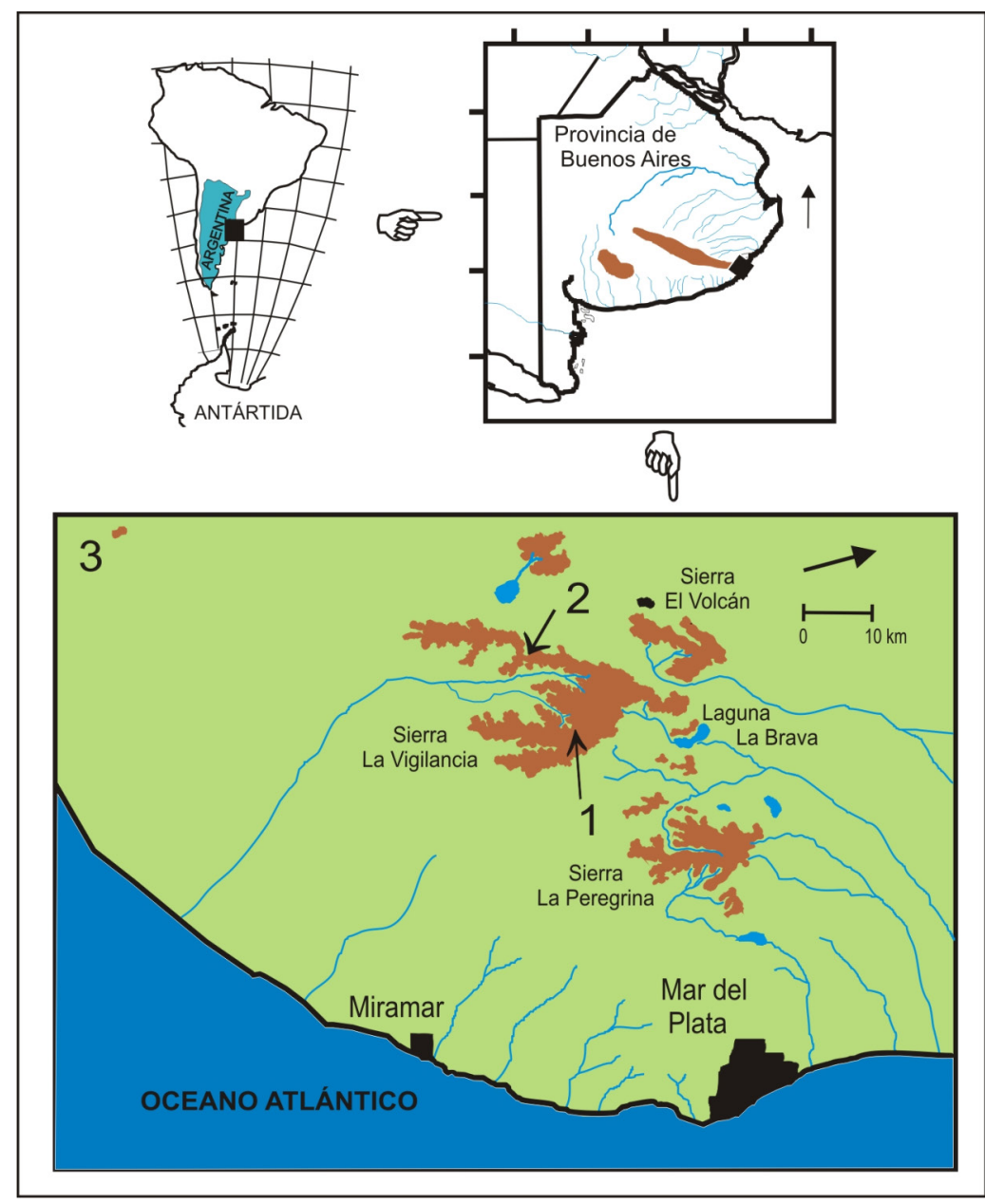

Figura 1. Ubicación geográfica de los principales sitios arqueológicos analizados del Holoceno tardío final de Tandilia oriental. 1, Cueva Tixi. 2, Cueva El Abra. 3, Lobería I. 
Entre el Pleistoceno tardío y el Holoceno temprano de Tandilia se identificaron ocupaciones caracterizadas por un comportamiento generalista de la subsistencia complementado, en el extremo occidental serrano, con la explotación ocasional de megamamíferos (Gutiérrez et al. 2010, Messineo y Politis 2009). Este patrón inicial fue transformado hacia la especialización de la caza de ungulados durante el Holoceno medio. La economía sustentada sobre venados y guanacos fue el tipo de relación con el medio más estable y duradero en la secuencia de Tandilia y coincide con procesos similares, basados sobre la caza del guanaco, ocurridos en otras zonas de la región (Politis 1984; Martínez y Gutiérrez 2004).

Diversos autores han coincidido en proponer que durante el Holoceno tardío de la región Pampeana ocurrió un cambio significativo en el modo de apropiación de los recursos animales (González 2005, Martínez 1999, Martínez y Gutiérrez 2004, Quintana y Mazzanti 2001, entre otros). En Tandilia Oriental la caza especializada se mantuvo durante la primera parte del Holoceno tardío, sin embargo hacia los 1000 AP la centralidad de los ungulados fue desplazada por un comportamiento que consistió en una explotación exhaustiva de los recursos faunísticos disponibles en el ambiente (Quintana y Mazzanti 2001; Quintana et al. 2003, 2002; Quintana 2005). Este nuevo comportamiento determinó un tipo de subsistencia establecido por la preponderancia de la caza de presas pequeñas, la complejización de los procesamientos carniceros y el uso de nuevas tecnologías, lo cual identifica la diversificación e intensificación del uso del espacio serrano.

Hace pocos años el estado del conocimiento arqueológico del Holoceno más tardío fue caracterizado acertadamente por Gustavo Martínez (1999) como “Con respecto al último lapso temporal elegido, 1000-500 AP, es difícil realizar cualquier tipo de apreciaciones debido a la escasez de sitios registrados, ya que sólo están implicados 500 años y por lo tanto la escala arqueológica es difícil de manejar..." Lejos de tomase como una sentencia desalentadora, este diagnóstico resultó un incentivo para profundizar en la riqueza de problemas involucrados en ese corto período y promover la búsqueda de nuevos contextos estratigráficos. En consecuencia, en diversas áreas de la región Pampeana el estudio de la arqueología del último milenio ha generado hipótesis que caracterizan el Holoceno tardío final como un momento de cambio crítico en la subsistencia de grupos cazadores recolectores y de las sociedades pastoriles registradas al final del período.

\section{Materiales y Métodos}

El análisis zooarqueológico de estos sitios comprendió la evaluación de las relaciones entre tipos distintos de presas, y la determinación de la diversidad del conjunto de presas pequeñas a través de dos índices (Quintana y Mazzanti 2010). El índice de Caza Mayor (ICM) permite medir la relación entre la captura de presas grandes y pequeñas. Para su cuantificación se consideraron como presas de la caza mayor a las que superan los $15 \mathrm{~kg}$ de masa y como presas de caza menor a las menores de esa magnitud: ICM: $\Sigma$ MNI caza mayor $/ \Sigma$ MNI caza mayor + caza menor y recolección

El índice de Diversidad de Caza Menor (IDCM) se construyó incorporando a las especies pequeñas en función de sus atributos de disponibilidad en el ambiente y su dificultad de obtención (Quintana y Mazzanti 2001; 2010; Quintana et al. 2002; Quintana 2005). De este modo, el foco del análisis son categorías de presas en lugar de taxones. Esta valoración permitió interpretar mejor el aporte de cada presa en el contexto de la subsistencia, para lo cual se definieron las siguientes categorías basadas sobre la capacidad de escape de presas 
pequeñas: lentas (Zaedyus pichiy, Chaetophractus villosus, Dasypus hybridus y huevos de Rhea americana), medias (Lagostomus maximus y Myocastor coypus) y rápidas (Galea tixiensis, Cavia aperea, Tupinambis merianae, Rhamdia sapo, y aves): IDCM: $\Sigma$ MNI presas lentas + medias / $\Sigma \mathrm{MNI}$ presas lentas + medias + rápidas

La discriminación analítica de dos modalidades de caza no implica disociar y fragmentar el estudio zooarqueológico, sino ponderar la información sobre estas dos actividades distintas y facilitar su integración analítica. La discusión y fundamentos de esta metodología están expuestos en detalle en Quintana y Mazzanti (2010).

Los materiales estudiados se encuentran depositados en la colección científica del Laboratorio de Arqueología de la Universidad Nacional de Mar del Plata.

\section{El registro arqueológico del Holoceno tardío final de Tandilia oriental}

Los sitios arqueológicos analizados y datados en el rango de los 1000 a los 700 años AP señalan la ocupación efectiva del territorio serrano y conducen al planteamiento de varias problemáticas relativas a los cambios en la estructura política-social y la complejidad manifestada en los modos establecidos por los cazadores-recolectores prehispánicos en ocupar este espacio del oriente pampeano. La visibilidad y cercanía a recursos críticos favorecieron la reocupación de los sitios, algunos de los cuales fueron demarcados con pictografías rupestres. Esta dinámica refuerza la idea de la estrategia de uso del paisaje y también es indicadora de los cambios que transitaban estas sociedades en su estructura social (Mazzanti 2006). En este sector serrano se descubrieron, a la fecha, más de diez sitios arqueológicos con contextos arqueológicos o indicadores que permiten su asignación a ese rango cronológico, entre los que se encuentran El Quebracho, Cerro de Bosch, Lobería I, La Cautiva Sitio 1 y 2, Cueva El Abra, Cueva Tixi, Los Difuntos Sitio 1 y 2, Abrigo Antú, Paredón Pancha, Haras Los Robles y Amalia Sitio 3 (Mazzanti 2006).

Estos sitios presentan características recurrentes en los modos de ocupar el paisaje, en la presencia de innovaciones tecnológicas y en el mayor tiempo de permanencia en los campamentos de las unidades domésticas. La arqueología del período incluye registros de gran diversidad de evidencias sobre la cultura material de este sector serrano. Los contextos se caracterizan por un mayor número de ítems, relacionados con la base económica y tecnológica, que permiten indagar las diversas actividades de trabajo llevadas a cabo dentro de los reparos rocosos (cuevas, abrigos y aleros). Se destacan dos tipos de asentamientos, aquellos que funcionaron como campamentos residenciales y los que fueron señalados a través del arte rupestre (Mazzanti 2006).

Los conjuntos arqueológicos provenientes de los sitios residenciales (Cueva Tixi, Cueva El Abra, Lobería I, Amalia sitio 3) permiten establecer que la vida doméstica en esos campamentos fue mediada por prácticas tecnológicas destinadas a intensificar la producción de diversos bienes. Los artefactos líticos se destinaron a usos múltiples, como los nuevos sistemas de armas especializadas para la caza (puntas triangulares apedunculadas pequeñas y medianas), de microlitos estandarizados para el trabajo sobre materias primas específicas y de otros tipos de instrumentos (raederas, raspadores, perforadores, cuchillos, muescas, manos de moler, etc.) (Mazzanti 2006). El uso de vasijas de cerámica fue significativo en estos campamentos residenciales, aunque aún no se hallaron indicadores de producción local. Con fragmentos de la alfarería se elaboraron instrumentos 
para hilar, posiblemente las fibras de los vellones de guanacos, lo cual sugiere la presencia de una práctica textil destinada a generar artículos de uso personal o bolsas para optimizar las recolecciones (Mazzanti y Puente 2014). También se produjeron punzones y retocadores sobre materiales orgánicos como huesos, además de adornos con valvas (cuentas) y se usaron huesos fosilizados, algunos decorados, de función desconocida por su estado fragmentado (Mazzanti 2006; Mazzanti y Valverde 2001).

Los pigmentos minerales fueron obtenidos en los afloramientos de Tandilia con el fin de producir pinturas destinadas a diversos soportes, especialmente para el arte rupestre, la cerámica y posiblemente para el tratamiento de las pieles y cueros (Mansur et al. 2009; Porto López y Mazzanti 2009). Algunos sitios conservan restos de estructuras de piedra destinadas al acondicionamiento del piso, un pequeño silo, parapetos y pircados para demarcar aguadas.

Algunas evidencias señalan situaciones de interacción social con poblaciones externas a este sector de la región Pampeana (Mazzanti 2006; Mazzanti y Porto López, 2007). Los contactos interregionales pudieron ser un componente sustancial en este proceso de cambio, involucrando aspectos de la movilidad y el carácter de las

\begin{tabular}{|c|c|c|c|c|c|c|c|c|c|}
\hline & \multicolumn{3}{|c|}{ Lobería I } & \multicolumn{3}{|c|}{ Cueva El Abra } & \multicolumn{3}{|c|}{ Cueva Tixi } \\
\hline & NISP & MNI & $\begin{array}{c}\text { MNI } \\
\%\end{array}$ & NISP & MNI & $\begin{array}{c}\text { MNI } \\
\%\end{array}$ & NISP & MNI & $\begin{array}{c}\text { MNI } \\
\%\end{array}$ \\
\hline Lama guanicoe & 75 & 5 & 10,86 & 18 & 2 & 1,41 & 66 & 3 & 2,01 \\
\hline Ozotoceros bezoarticus & 178 & 2 & 4,34 & 113 & 2 & 1,41 & 100 & 2 & 1,34 \\
\hline Caviinae & 222 & - & - & 2814 & - & - & 1850 & - & - \\
\hline Galea tixiensis & 42 & 7 & 15,22 & 199 & 63 & 44,68 & 245 & 85 & 57,04 \\
\hline Cavia aperea & 29 & 6 & 13,04 & 89 & 35 & 24,82 & 79 & 26 & 17,44 \\
\hline Lagostomus maximus & 382 & 13 & 28,26 & 468 & 12 & 8,51 & 180 & 6 & 4,02 \\
\hline Myocastor coypus & - & - & & 17 & 3 & 2,12 & 4 & 2 & 1,34 \\
\hline Zaedyus pichiy & 32 & 1 & 2,17 & 108 & 1 & 0,7 & 228 & 1 & 0,67 \\
\hline Chaetophractus villosus & 769 & 2 & 4,34 & 2230 & 5 & 3,54 & 1972 & 4 & 2,68 \\
\hline Dasypus hybridus & 1208 & 3 & 6,52 & 783 & 2 & 1,41 & 413 & 1 & 0,67 \\
\hline Tupinambis cf. merianae & 45 & 2 & 4,34 & 279 & 6 & 4,25 & 150 & 7 & 4,7 \\
\hline Puma concolor & - & - & & - & - & & 1 & 1 & 0,67 \\
\hline Rhamdia sapo & - & - & & 3 & 1 & 0,7 & 8 & 1 & 0,67 \\
\hline Rhea americana & 6 & 1 & 2,17 & 1 & 1 & 0,7 & 1 & 1 & 0,67 \\
\hline Rhea americana (huevos) & & 1 & 2,17 & - & 3 & 2,12 & - & 3 & 2,01 \\
\hline Aves indeterminadas & 4 & 3 & 6,52 & 10 & 5 & 3,54 & 10 & 6 & 4,02 \\
\hline
\end{tabular}

Tabla 1. Diversidad de recursos incorporados a la subsistencia durante el Holoceno tardío final de Tandilia Oriental. 
relaciones sociales que establecieron estos grupos durante los últimos milenios previos a la conquista. En Tandilia oriental los contactos extra regionales están indicados por la presencia de fragmentos carbonizados de mazorca y semillas de Zea maiz en Cueva Tixi y por obsidiana y cerámica con inclusiones alóctonas en cueva El Abra (Mazzanti 2005; Zucol et al. 2005).

En Tandilia oriental los sitios arqueológicos del Holoceno tardío final con registro de restos faunísticos son Cueva El Abra Componente Superior (958 \pm 32 AP, AA 33419), Cueva Tixi Nivel Arqueológico 4 (715 \pm 45 AP, AA15809) y Lobería I Superior (entre $676 \pm 41$ AP, AA81060 y $883 \pm 41$ AP, AA81059) (Tabla 1) (Figura 1).

La subsistencia de este período muestra cierta homogeneidad propia de esta región serrana, la cual fue analizada enfatizando sobre los dos sistemas de obtención de recursos preponderantes: la caza mayor y la caza menor.

\section{Caza Mayor}

En los tres sitios analizados se registraron las mismas especies incorporadas a esta modalidad de caza: guanaco, venado de las pampas y ñandú (Tabla 1 y 2). Esto representa una continuidad de la tradición de los milenios previos en los que esos ungulados conformaron el núcleo de la especialización de la subsistencia y el ñandú era usado como una presa ocasional. Antes bien, la importancia relativa de la explotación de especies grandes, expresada a través del índice de Caza Mayor, indica un cambio en la subsistencia respecto de otras ocupaciones más tempranas (Figura 2). Este cambio se manifiesta simultáneamente por la captura proporcional de más individuos de especies pequeñas y de menos presas grandes.

\begin{tabular}{|r|c|c|c|c|}
\hline & $\begin{array}{c}\text { Huellas } \\
\text { de Corte }\end{array}$ & $\begin{array}{c}\text { Exposición } \\
\text { al Fuego }\end{array}$ & $\begin{array}{c}\text { Fractura } \\
\text { Intencional }\end{array}$ & $\begin{array}{c}\text { Tecnología } \\
\text { ósea }\end{array}$ \\
\hline Lama quanicoe & $\mathrm{X}$ & $\mathrm{X}$ & $\mathrm{X}$ & $\mathrm{X}$ \\
\hline Ozotoceros bezoarticus & $\mathrm{X}$ & $\mathrm{X}$ & $\mathrm{X}$ & $\mathrm{X}$ \\
\hline Galea tixiensis & $\mathrm{X}$ & $\mathrm{X}$ & - & - \\
\hline Cavia aperea & $\mathrm{X}$ & $\mathrm{X}$ & - & - \\
\hline Lagostomus maximus & $\mathrm{X}$ & $\mathrm{X}$ & $\mathrm{X}$ & $\mathrm{X}$ \\
\hline Muocastor coupus & $\mathrm{X}$ & $\mathrm{X}$ & - & $\mathrm{X}$ \\
\hline Zaeduus pichiu & - & $\mathrm{X}$ & - & - \\
\hline Chaetophractus villosus & $\mathrm{X}$ & $\mathrm{X}$ & - & - \\
\hline Dasupus hubridus & $\mathrm{X}$ & $\mathrm{X}$ & - & - \\
\hline Tupinambis cf. merianae & $\mathrm{X}$ & $\mathrm{X}$ & $\mathrm{X}$ & $\mathrm{X}$ \\
\hline Rhamdia sapo & - & $\mathrm{X}$ & - & - \\
\hline Rhea americana & $\mathrm{X}$ & $\mathrm{X}$ & - & - \\
\hline Rhea americana huevos) & - & $\mathrm{X}$ & - & - \\
\hline Aves medianas & $\mathrm{X}$ & $\mathrm{X}$ & - & $\mathrm{X}$ \\
\hline
\end{tabular}

Tabla 2. Tipo de evidencias halladas en las especies incorporadas a la subsistencia durante el Holoceno tardío final de Tandilia Oriental. 
Durante este período el procesamiento de guanacos y de venados, además, se diferencia del período anterior por una gran fragmentación, el aprovechamiento exhaustivo de la carcasa y una tecnología ósea especializada (Quintana y Mazzanti 2001; Mazzanti et al. 2010; Quintana et al. 2003). En los tres sitios el registro de ungulados presenta pocos huesos enteros, en general piezas correspondientes a los autopodios, lo que caracteriza una tendencia general de poca o nula correlación de la utilidad económica (con pendiente negativa en ambas especies y en todos los sitios) (Tabla 3). Este patrón es, en apariencia, consecuente con una estrategia de utilidad negativa característica de sitios de matanza. Antes bien, la gran fragmentación, la abundancia de astillas de diáfisis y el procesamiento de las falanges resultan de la gran intensidad del procesamiento aplicado sobre estos animales. La distribución de tamaños de las astillas permite reconocer el tratamiento del esqueleto para obtener carne, médula y grasa ósea (Figura 3). Por ejemplo el análisis preliminar de una muestra de 3822 elementos de Lobería I muestra que el 96,75\% (3696) son astillas de las cuales el 89,5\% son menores a 3 centímetros. La relación entre el NISP y el peso está altamente correlacionada $(\mathrm{ccc}=0,98)$ habiéndose preservado principalmente astillas de diáfisis $(92,5 \%)$ y el resto se reparte entre fragmentos de costillas, hueso esponjoso, huesos enteros y partes identificables anatómicamente. Este mismo patrón de elementos de ungulados, como consecuencia del procesamiento intensivo, se encuentra en Cueva El Abra y en Cueva Tixi el cual habría tendido al aprovechamiento total de la carcasa para el consumo de carne, médula y grasa ósea, incluso de las partes menos nutritivas (Outram 2001). El carácter fragmentario de los huesos, que ocasiona pérdida de información de huellas de corte y dificultad para identificar piezas anatómicas, impide analizar con más detalle las acciones de carnicería.

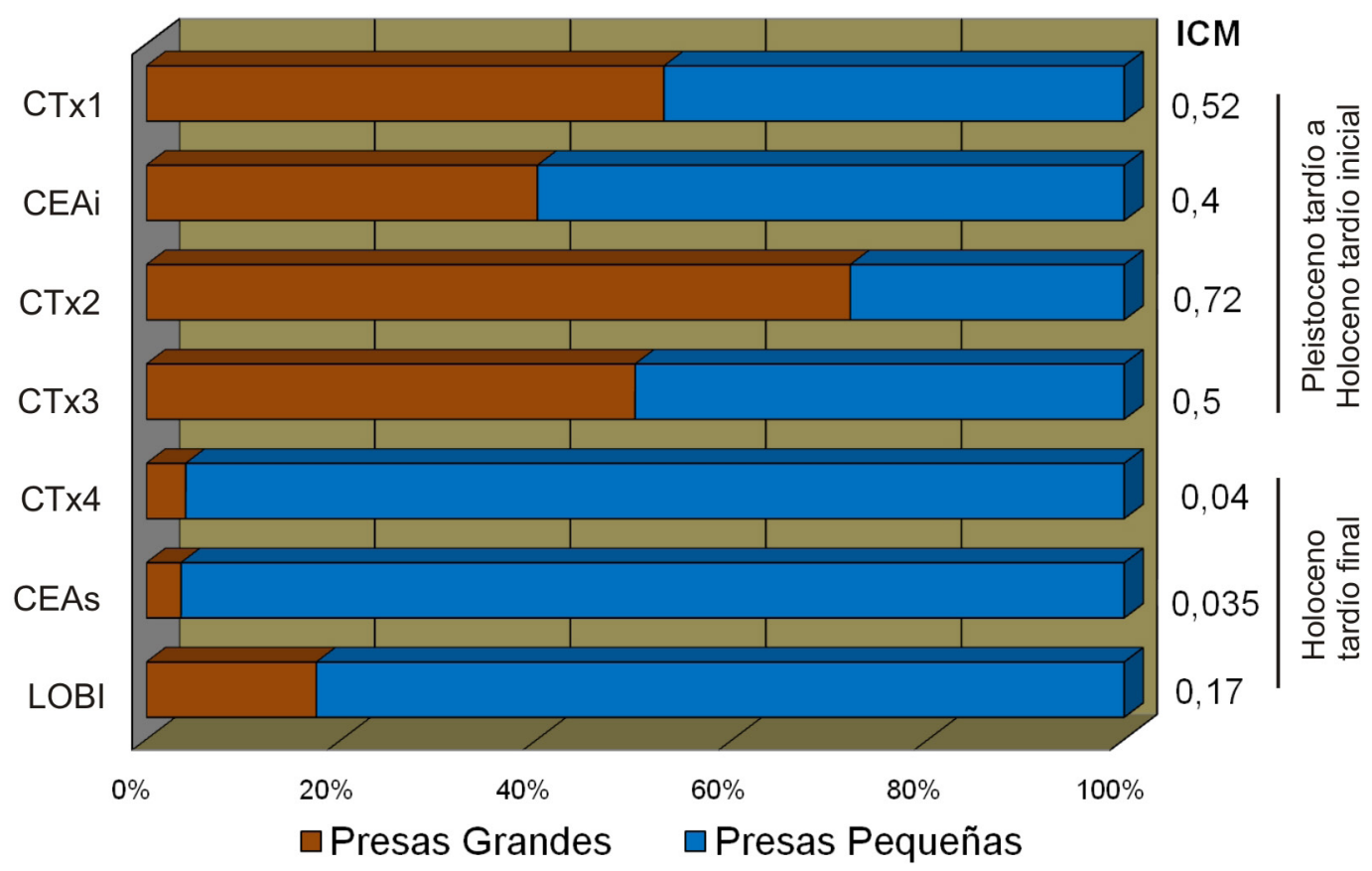

Figura 2. Contribución de cada clase de presas al índice de Caza Mayor de los sitios del Holoceno tardío final de Tandilia Oriental comparado con ocupaciones más tempranas. ICM: Índice de Caza Mayor. CTx1: Cueva Tixi nivel arqueológico 1. CTx2: Cueva Tixi nivel arqueológico 2. CTx 3: Cueva Tixi nivel arqueológico 3. CTx 4: Cueva Tixi nivel arqueológico 4. CEAs: Cueva El Abra Componente superior. LOB I: Lobería I Ocupación superior. 


\begin{tabular}{|c|c|c|c|c|}
\hline & \multicolumn{2}{|c|}{ Guanaco } & \multicolumn{2}{|c|}{ Venado } \\
\hline & Carne/Médula & Densidad & Carne/Médula & Densidad \\
\hline Lobería I & $\begin{array}{l}\text { rho }=-0,13 \\
P<0,01\end{array}$ & $\begin{array}{l}\text { rho }=0,45 \\
P<0,01\end{array}$ & $\begin{array}{l}\text { rho }=-0,42 \\
P<0,01\end{array}$ & $\begin{array}{l}\text { rho }=0,13 \\
\mathrm{P}<0,01\end{array}$ \\
\hline Cueva El Abra & & & $\begin{array}{l}\text { rho }=-0,23 \\
\mathrm{P}<0,01\end{array}$ & $\begin{array}{l}\mathrm{rho}=0,10 \\
\mathrm{P}<0,01\end{array}$ \\
\hline Cueva Tixi & $\begin{array}{l}\text { rho }=-0,38 \\
P<0,01\end{array}$ & $\begin{array}{l}\text { rho }=0,01 \\
\mathrm{P}<0.01\end{array}$ & $\begin{array}{l}\mathrm{rho}=-0,42 \\
\mathrm{P}<0.01\end{array}$ & $\begin{array}{l}\text { rho }=0,001 \\
\mathrm{P}<0,01\end{array}$ \\
\hline
\end{tabular}

Tabla 3. Correlación del MAU\% de guanaco (Lama guanicoe) y venado de las pampas (Ozotoceros bezoarticus) respecto de la utilidad económica (índice de carne/médula) y de la densidad global ósea de los sitios del Holoceno tardío final de Tandilia Oriental.

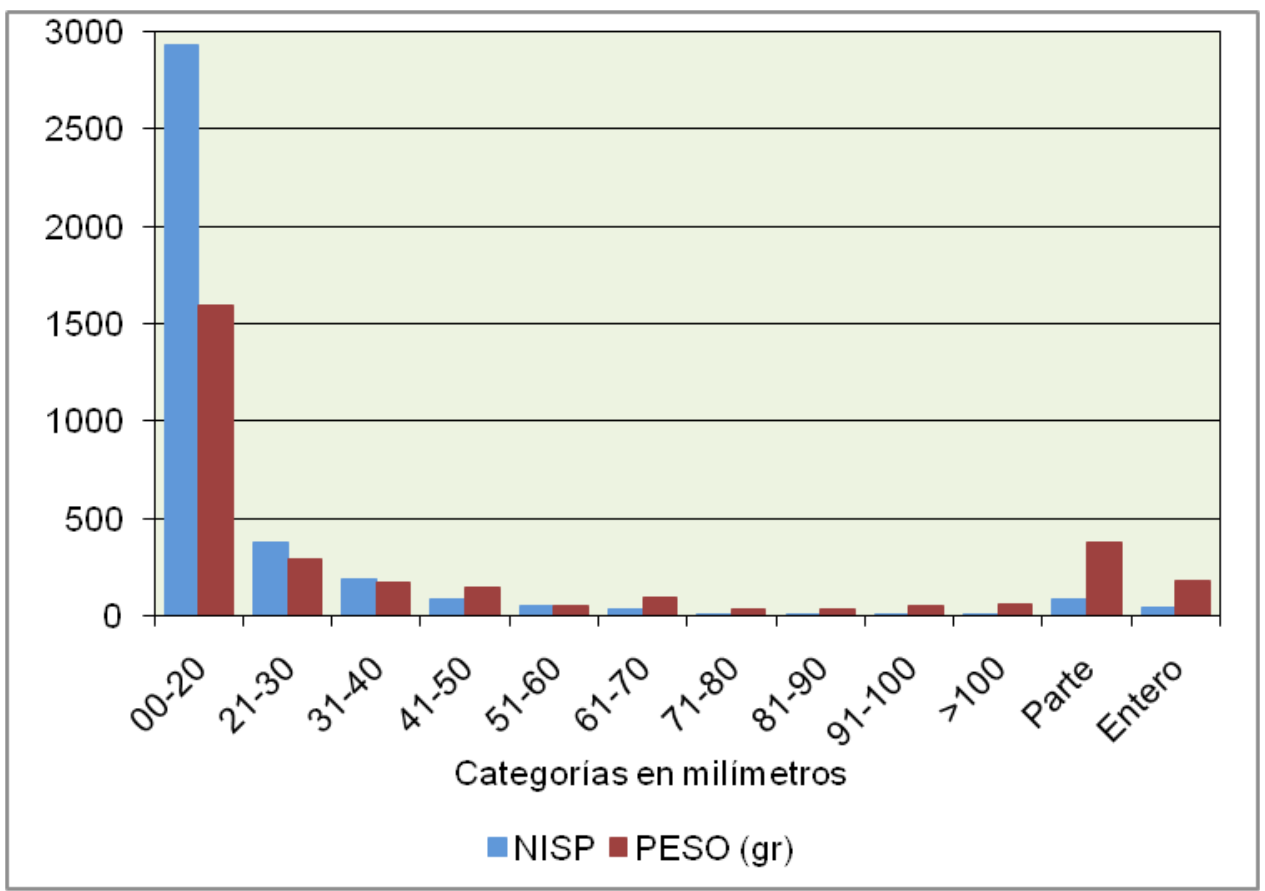

Figura 3. Distribución de tamaños y pesos, en clases de 10 milímetros, de una muestra de 3822 elementos de ungulados de la Ocupación superior de Lobería I. Parte: fragmento identificable anatómicamente. Entero: elemento anatómicamente completo.

Los pocos restos de ñandú, todos referidos a los elementos distales de los miembros, principalmente falanges, indican que estas presas no habrían ingresado enteras a los sitios y que, al menos, se habrían aprovechado los tendones. En Cueva Tixi se registró un metapodio de puma con huellas de corte, pero esta evidencia es muy escasa para interpretar el rol de esta especie en ese contexto.

Entre estos sitios, Lobería I es el que presenta una caza más acentuada de guanaco y venado, si bien a través del MNI no es muy evidente (Tabla 1) su cuantificación respecto del resto de la fauna explotada y en el índice de Caza Mayor muestra el contraste en un orden de magnitud respecto de los otros sitios (Figura 2). 
En este contexto, la caza de especies grandes se mantuvo durante el Holoceno tardío final para acceder a fuentes destacadas de alimentos y de materias primas, pero su rol habría estado condicionado por una nueva dinámica social de los asentamientos humanos y un probable aumento poblacional. La caza mayor está representada sólo entre el 3,5\% y el 17\% de las presas capturadas (Figura 2), en consecuencia su análisis excluyente de otros tipos de presas no permite identificar ni conocer en mayor profundidad la subsistencia de este período en Tandilia oriental. Antes bien, queda establecido en los tres sitios el cambio de una estrategia jerárquica especializada en la apropiación de ungulados, que caracterizó la subsistencia de milenios previos en Tandilia, hacia una estrategia de conjunto en la que los ungulados sólo son una parte del objetivo buscado en las partidas de caza durante el Holoceno tardío final.

\section{Caza Menor}

La caza menor durante el Holoceno tardío final en Tandilia oriental fue preponderante frente a la caza mayor (Figura 2), involucró la captura de cuises, vizcacha, coipo, lagarto overo, armadillos, aves, peces y la recolección de huevos de ñandú (Tabla 1). Las evidencias de su explotación comprenden huellas de corte y de raspado, fracturas intencionales, transformación de huesos en artefactos y exposición al fuego (Tabla 2). La ubicación topográfica de estos sitios es incongruente con la presencia de peces y de huevos de ñandú, por lo que, junto a las alteraciones térmicas y ausencias de evidencias de predadores, se infiere su traslado antrópico.

A diferencia de la explotación de los ungulados las especies pequeñas incorporadas a la subsistencia de este período presentan procesamientos más heterogéneos, aunque dentro de un mismo patrón de aprovechamiento. Algunas de estas presas (cuises, vizcacha y lagarto) cuentan con un registro numeroso y con buena calidad de preservación, lo que permitió la resolución de la secuencia de procesamiento (Quintana 2005; Quintana y Mazzanti 2011). En esas especies se determinaron procedimientos complejos que involucraron desollamiento, desmembramiento y descarne. En el caso de la vizcacha y del lagarto, además, se documentaron fracturas intencionales y el uso de los huesos en la tecnología ósea. El tipo de desollamiento determinado en los cuises y en las vizcachas indica que las pieles fueron retiradas de un modo cuidado y preciso para destinarlas a algún uso posterior.

Las otras especies pequeñas no cuentan con la suficiente cantidad de restos para plantear secuencias de procesamiento completas. Antes bien, algunas huellas de corte sugieren descarne y desarticulación secundaria en el caso de los armadillos, y desarticulación de la mandíbula en el coipo. En este grupo con menos disponibilidad de evidencias se identificaron huesos que fueron modificados para su uso como artefacto en el caso de las aves y el coipo.

La incorporación de las especies pequeñas a los sitios parece homogénea desde el aspecto de la riqueza taxonómica (Tabla 1), sin embargo al ser analizada en tanto que categorías de presas se evidencian variaciones internas en función de su contribución al índice de Diversidad de Caza Menor (Figura 4).

Estos sitios, que se ubican en sectores diferentes del paisaje serrano, presentan variaciones condicionadas por la disponibilidad espacial y estacional de las presas. Las diferencias entre los conjuntos se expresan principalmente en Lobería I respecto de las otras dos cuevas. 
Entre Cueva Tixi y Cueva El Abra esta variación es despreciable, ambos sitios tienen la misma diversidad de especies pequeñas que componen a cada categoría, y con valores absolutos muy parecidos (Figura 4). En estos dos sitios la categoría rápida es particularmente importante ya que contribuye con más del $80 \%$ de la variabilidad de las presas capturadas, lo que implica a decenas de ejemplares que influyen notoriamente en el algoritmo (Tabla 1). La categoría intermedia diferencia a ambos sitios en tanto que es algo mayor en Cueva El Abra, en función del énfasis en la caza de vizcacha, mientras que las especies lentas tienen una composición numérica y taxonómica similar en las dos cuevas (Figura 4).

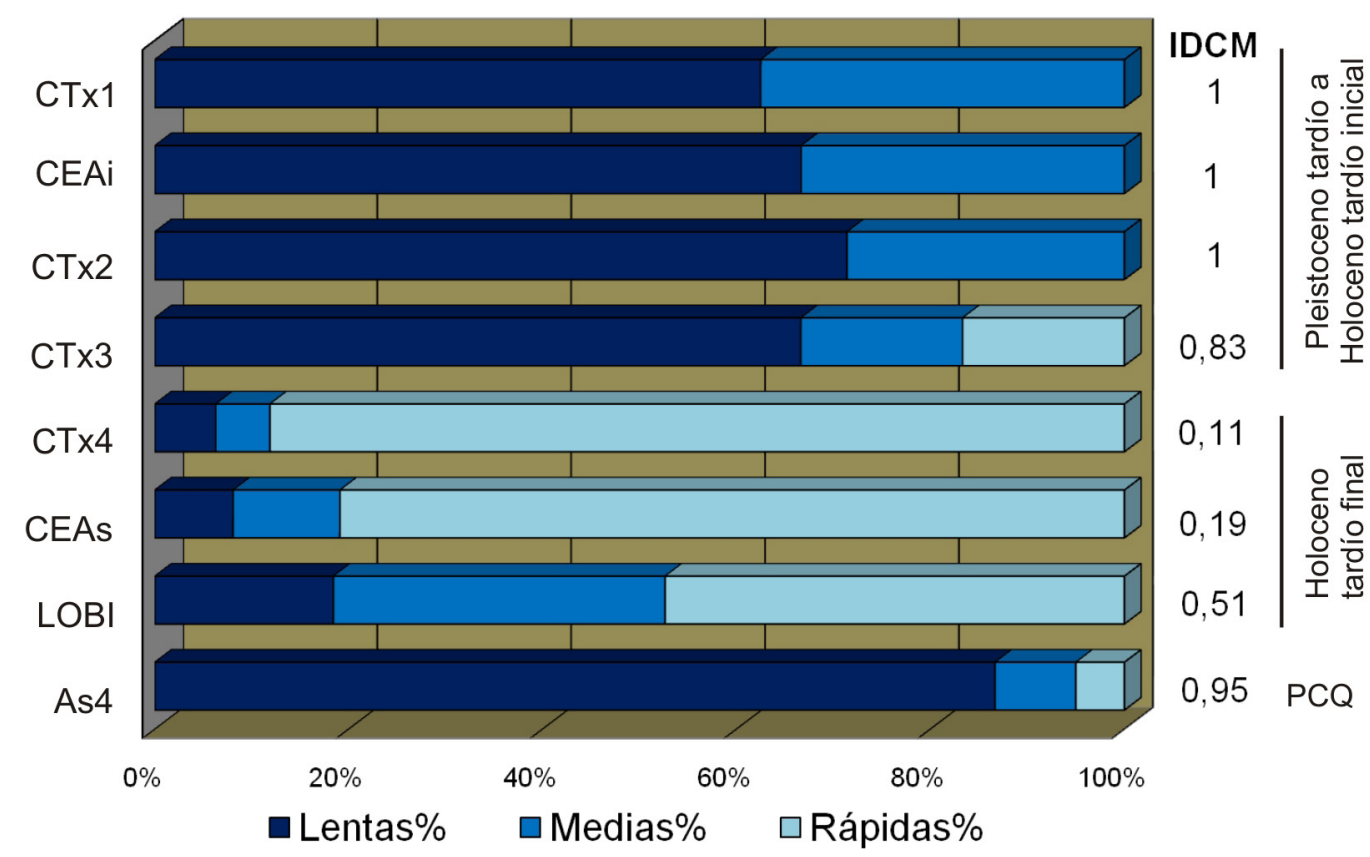

Figura 4. Contribución proporcional de cada categoría de presas a la Caza Menor de los sitios del Holoceno tardío final de Tandilia Oriental comparado con ocupaciones más tempranas. IDCM, Índice de Diversidad de Caza Menor. PCQ: Posconquista. CTx1: Cueva Tixi nivel arqueológico 1. CTx2: Cueva Tixi nivel arqueológico 2. CTx 3: Cueva Tixi nivel arqueológico 3. CTx 4: Cueva Tixi nivel arqueológico 4. CEAs: Cueva El Abra Componente superior. LOB I: Lobería I Ocupación superior. AS4: Amalia Sitio 4.

Lobería I se caracteriza por presentar el índice de Diversidad de Caza Menor más alto de los tres sitios analizados aunque se mantiene dentro de valores bajos y característicos de contextos de gran incidencia de especies pequeñas, en comparación con otras ocupaciones pampeanas más antiguas en los que adquiere magnitudes mayores (Figura 2 y 4). En este sitio la composición de la caza menor se caracteriza por: la categoría rápida carece de peces, la categoría intermedia no tiene registro de coipo y el resto de los taxones aportan MNI bajos (Tabla 1). La contribución de cada categoría al índice muestra esta situación, ya que las presas rápidas adquieren la mitad del valor que en los otros dos sitios, lo que indica que las decisiones de captura se hayan corrido en un $40 \%$ hacia las presas lentas y media (Figura 4). El aporte de la categoría media a la formación del índice es importante, a pesar que se compone de una sola especie, porque adquiere un valor muy alto $(\mathrm{MNI} \%=28,26)$ 
con relación al tamaño de la muestra y en comparación con el registro de las otras cuevas, es decir, esta categoría fue cazada más exhaustivamente. Con las especies lentas también ocurre una situación similar, los armadillos adquieren una importancia proporcional elevada en el conjunto de las presas consumidas, mientras que los huevos de ñandú fueron menos importantes numéricamente.

Durante el período analizado la caza menor aporta la mayor cantidad y diversidad de especies al mismo tiempo que se comporta como el conjunto más sensible de fuente de información del tipo de subsistencia. La obtención de presas pequeñas durante tiempos tardíos de Tandilia oriental involucró el desarrollo de decisiones de captura de especies de tallas con diferencias de dos órdenes de magnitud, la intervención sobre distintos componentes del paisaje (arroyos, pendientes, mesetas, lomas, valles) y sobre estructuras diversas de esos ámbitos (superficie, madrigueras, cursos y bordes de arroyos) (Figura 5). Este panorama condicionó la aplicación de técnicas de caza y la adecuación de los modos de procesamiento en presas disímiles como cuises, peces, lagartos y armadillos.

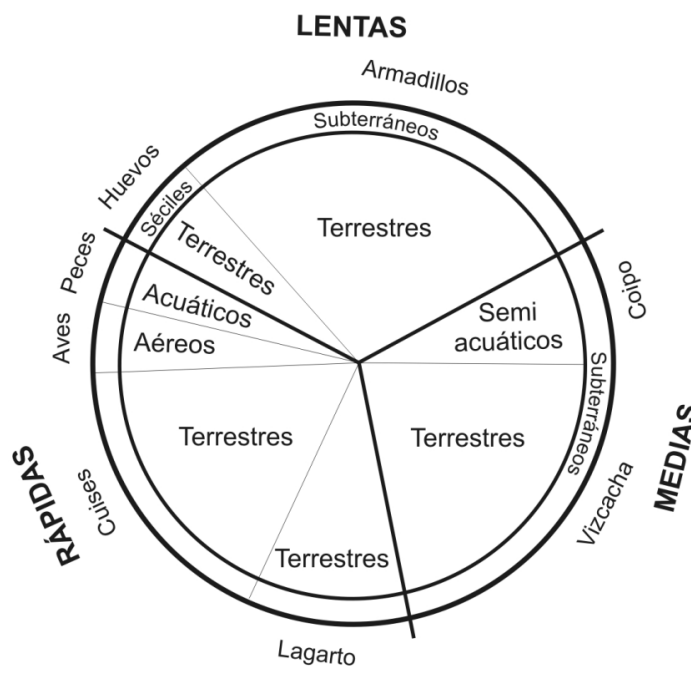

Caza Menor

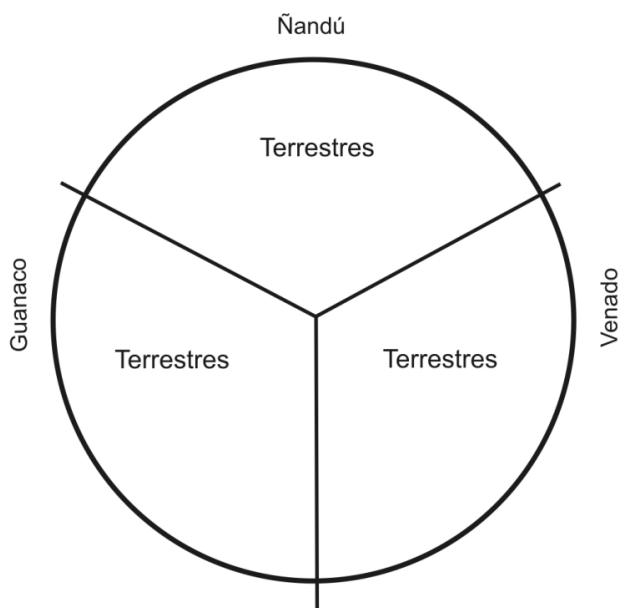

Caza Mayor

Figura 5. Diversidad ambiental de las presas de los sitios del Holoceno tardío final de Tandilia Oriental.

\section{Diversificación e intensificación en Tandilia Oriental}

Entre las tres ocupaciones se reconocen algunas diferencias en la explotación de recursos, si bien no se espera que cada sitio tenga un patrón idéntico, en este caso la ubicación geográfica y la estacionalidad son variables que pudieron contribuir a esa disimilitud. Cueva Tixi y Cueva El Abra están enclavadas a media altura de pendientes serranas, con buena visibilidad del entorno y en cercanías de cuerpos de agua permanentes y temporarios. La primera cueva se dispone dentro de un valle principal y la segunda en un abra en la salida de otro gran valle adyacente (Figura 1). Lobería I es una cueva en la base de un peñón dispuesto en una zona de lomas bajas y con menor visibilidad y 
heterogeneidad ambiental. Este enclave se presenta a modo de una "isla" en el contexto del paisaje serrano regional, similar a los cerros Amalia y La Cautiva (Mazzanti 2007), lo que influye en su menor diversidad micro ambiental y, en consecuencia, en la disponibilidad de determinadas especies.

La principal fuente de diversidad de la explotación en Tandilia Oriental es el uso de coipo y peces sólo en Cueva Tixi y Cueva El Abra, seguido de la menor incorporación de lagartos, cuises y huevos de ñandú en Lobería I (Tabla 1, Figura 4). La explotación de la vizcacha es importante dentro de la caza menor ya que presenta cantidades elevadas de ejemplares en cada sitio (Quintana y Mazzanti 2011). Las poblaciones de vizcacha ocupan casi todos los ámbitos del paisaje serrano, excepto las pendientes y cursos de agua, por lo que junto a su distribución de escasa vagilidad, al generar colonias subterráneas se comportan como recursos estables y predecibles del ambiente. Estas propiedades convierten a estos roedores en presas atractivas y relativamente fáciles de capturar con tecnología diversa, ya sean elementos arrojadizos o trampas, y están disponibles en todas las épocas del año en distancias cercanas a los sitios.

La ausencia en Lobería I de presas lacustres, como el coipo y los peces, responde a esta variable mientras que la disminución de la captura de cuises es menos evidente pero podría estar vinculada al mismo motivo geográfico. Hay dos factores estacionales que pudieron afectar a la composición de la abundancia relativa de las presas en Lobería I. Por un lado, las vizcachas tienen un comportamiento social que aumenta el tiempo de actividad fuera de las madrigueras en invierno (Branch 1993) por lo que están más expuestas a la caza (Quintana y Mazzanti 2011). A su vez, los lagartos overos hibernan entre los meses de Abril a Septiembre (Duarte y Cabrera 2000) lo cual coincide con el período en que no hay huevos de ñandú disponibles. Si Lobería I fue ocupada principalmente durante los meses fríos es concordante con el alto número mínimo de individuos de vizcacha asociado a la baja abundancia de lagartos y huevos de ñandú, comparado con los otros dos sitios. Esta situación indica que en Lobería I la vizcacha actuó como un recurso amortiguador frente a la disminución de las especies de la categoría rápida (lacustres, lagartos y cuises) (Quintana y Mazzanti 2011). Como se menciona más arriba, la caza de ungulados si bien es más acentuada en este sitio no es central como en el caso de los sistemas especializados.

Las propiedades intrínsecas de las especies como el tamaño poblacional, el ciclo reproductivo, la talla, la estacionalidad, la ubicación en el paisaje, la disponibilidad de carne y médula, entre otras, son invariantes y permiten generar un ordenamiento valorativo en tanto que presas. Sin embargo, la diversidad descripta en este sector serrano muestra que las mismas especies pueden ser objeto de intereses de caza distintos, por lo que ese ordenamiento es mutable. Como ya se mencionó, la posición de los sitios en el ambiente es un condicionante del acceso a determinadas poblaciones de modo que, por ejemplo, el coipo adquiere un valor pos captura mayor en Cueva Tixi o Cueva El Abra que en Lobería I. Mientras, en este sitio, se optimiza la explotación de la vizcacha y de armadillos respecto de las especies de microvertebrados.

Esta variabilidad intersitio indica la adecuación de las partidas de caza a su micro entorno, en el contexto del sostenimiento de un mismo tipo de estrategia de subsistencia. Así, la variabilidad en la explotación de recursos entre Lobería I y las otras cuevas no sugiere la propuesta de estrategias de subsistencia diferentes entre los dos grupos de sitios, la heterogeneidad interna detectada en esta micro región es menor que la conocida 
inter regionalmente. Los tres sitios arqueológicos, además, presentan contextos similares caracterizados por ocupaciones prolongadas, presencia de pictografías, alfarería, artefactos líticos muy pequeños, incorporación del arco con diversidad de puntas de proyectil y de tecnología ósea y desarrollo de hilado.

En este marco, la subsistencia del Holoceno tardío final de Tandilia oriental presenta recurrencias que permiten su caracterización.

Se destaca la captura y uso de nuevas presas. Son especies que estuvieron presentes en el paisaje desde el Holoceno temprano pero que fueron excluidas por las sociedades cazadorasrecolectoras, o su incorporación al conjunto explotado fue mínima o extremadamente ocasional como para dejar evidencias. En cualquier caso, durante ese lapso se comportaron a modo de recursos de reserva que pasaron a tener importancia social y visibilidad arqueológica en las condiciones del Holoceno más tardío. En Cueva Tixi se detectaron al menos cuatro especies de este tipo: el lagarto overo (T. merianae), los cuises (G. tixiensis y C. aperea), el bagre (R. sapo), a las que deben sumarse las aves (Quintana y Mazzanti 2001; Quintana et al. 2002; Quintana 2005). En Cueva El Abra y Lobería I ocurre un fenómeno similar, con la excepción del uso de peces en el último sitio.

El procesamiento complejo y exhaustivo de algunas especies pequeñas es característico del Holoceno tardío final prehispánico, ya que no fue registrado en tiempos precedentes ni posteriores. Esos procesos no fueron homogéneos, la principal variación se refiere a la fractura de huesos largos y su inclusión en la tecnología ósea sólo en las especies pequeñas más grandes.

Otra característica de la diversificación e intensificación de la subsistencia en Tandilia Oriental es el aumento significativo de la cantidad de especies pequeñas capturadas de todas las categorías. Este fenómeno se observa desde diversas fuentes: el aumento del NISP, del MNI, y proporcionalmente desde el MNI\% (Tabla 1). Además, el Índice de Caza Mayor muestra que las decisiones de caza sobre presas pequeñas fueron preponderantes, entre el 83 y el 96\% (Figura 2). En otras ocupaciones serranas la incorporación de especies pequeñas se encuentra entre el $28 \%$ y el $60 \%$ siendo magnitudes similares a ocupaciones de otras áreas con tipos de subsistencia diferentes (Figura 2). Los mamíferos pequeños se caracterizan por tener ciclos de vida más parecidos a especies estrategas " $\mathrm{r}$ ", es decir, menos longevas pero con más pariciones al año y más crías por parición. Si bien el rendimiento absoluto por unidad de captura es menor en este tipo de presas, su aprovechamiento se ve favorecido por su mayor disponibilidad y predictibilidad en el paisaje, en conjunto con su mejor capacidad de soportar predaciones intensas.

La caza mayor se presenta deprimida en comparación con los milenios anteriores (Figura 2). Sin embargo se mantiene la caza de las mismas presas grandes, aunque con procesamientos más exhaustivos que alteran los huesos por fracturas intencionales más numerosas, procedimientos de cocción más destructivos y su mayor uso en la tecnología ósea (Tabla 3).

La intensificación y diversificación en esta región incorpora la explotación de animales de la categoría rápida (peces, cuises, aves y lagartos) que se caracterizan por la alta capacidad de evasión en situaciones de amenaza (Figura 4). Entre estos organismos se manifiesta la diversidad de recursos para la fuga que complementan a la rapidez: tallas pequeñas, 
ocultamiento, comportamientos comunitarios, vuelo, nado, etc., lo cual condiciona y diversifica las técnicas y tecnologías de caza por lo que su captura requiere del desarrollo de metodologías y de elementos específicos.

En el contexto del aumento de la captura de especies pequeñas, la explotación de especies menores a $1 \mathrm{~kg}$ es una novedad que surge durante este lapso. La incorporación de microvertebrados representaría un umbral sólo superado en condiciones de extrema necesidad de optimizar los recursos del ambiente, siendo un claro indicador de un momento pleno de diversificación de la elección de recursos e intensificación de la subsistencia. La inclusión de microvertebrados a la dieta tiene otros significados en la dinámica de la subsistencia y cronologías más tempranas de otras regiones (Medina et al. 2011). Los huevos de ñandú son el único organismo entre los microvertebrados que se explota desde el Pleistoceno tardío, pero su situación estática que requiere un mínimo esfuerzo para su obtención y el alto aprovechamiento de cada unidad, entre el 80 y el $90 \%$ de su masa (Quintana 2008), diferencia a este recurso del resto de los microvertebrados consumidos en Tandilia. Los demás microvertebrados hallados en los tres sitios carecen de cualquier evidencia de manipulación antrópica (Quintana y Mazzanti 2001; Quintana 2015).

\section{La intensificación y diversificación como proceso regional}

La subsistencia del Holoceno tardío de la pampa húmeda fue caracterizada a través del establecimiento de "economías areales de diversificación e intensificación" (Martínez 1999; Martínez y Gutiérrez 2004), es decir del desarrollo de un mismo fenómeno social que presenta rasgos distintivos entre las áreas de la región. Aplicando los índices utilizados para describir los atributos de la caza en Tandilia oriental sobre algunos sitios arqueológicos de la región Pampeana, se advierte un patrón regional de dos grupos en función de la cronología y de la relación entre los tipos de presas (Figura 6). Los sitios que fueron interpretados con subsistencias de intensificación y diversificación presentan cronologías tardías, contextos arqueológicos similares y la caza menor numerosa y variada, lo cual es consistente con la propuesta de regionalización económica. Mientras que el otro grupo tiene características arqueológicas y cronologías más diversas y tempranas, tipos de subsistencia diferentes y la caza menor es nula o despreciable.

Los sitios arqueológicos tardíos de Tandilia oriental presentan similitudes con la subsistencia planteada en la Depresión del Río Salado (González 1994, 2005), en la Zona Norte de la provincia de Buenos Aires (Paleo et al. 2002) y en el curso inferior del Río Colorado (Martínez 2004; Martínez et al. 2005). En estas áreas, además, se ha descripto un modelo de subsistencia tardío con características propias y con variabilidad interna en la explotación intensa de fauna. Esta variabilidad también está relacionada con factores geográficos y con la disponibilidad de recursos, por ejemplo entre la costa y el continente, o entre distintos cuerpos de agua (Salemme et al. 2012; Frontini 2013; Martínez y Gutiérrez 2004; Martínez et al. 2010).

Los sitios tardíos de la Depresión del Río Salado (ca. 500 a 1200 AP) están caracterizados por la explotación de recursos pequeños y, principalmente, fluviales: coipo, aves acuáticas y peces en sitios ocupados densamente, con intensa producción de alfarería y tecnología lítica (González 1994, 2005). En esa cuenca las especies involucradas son distintas a las cazadas en la zona serrana ya que las aves y los peces son preponderantes, sólo coinciden en la explotación del bagre, el coipo y el venado de las pampas. Estas diferencias están 


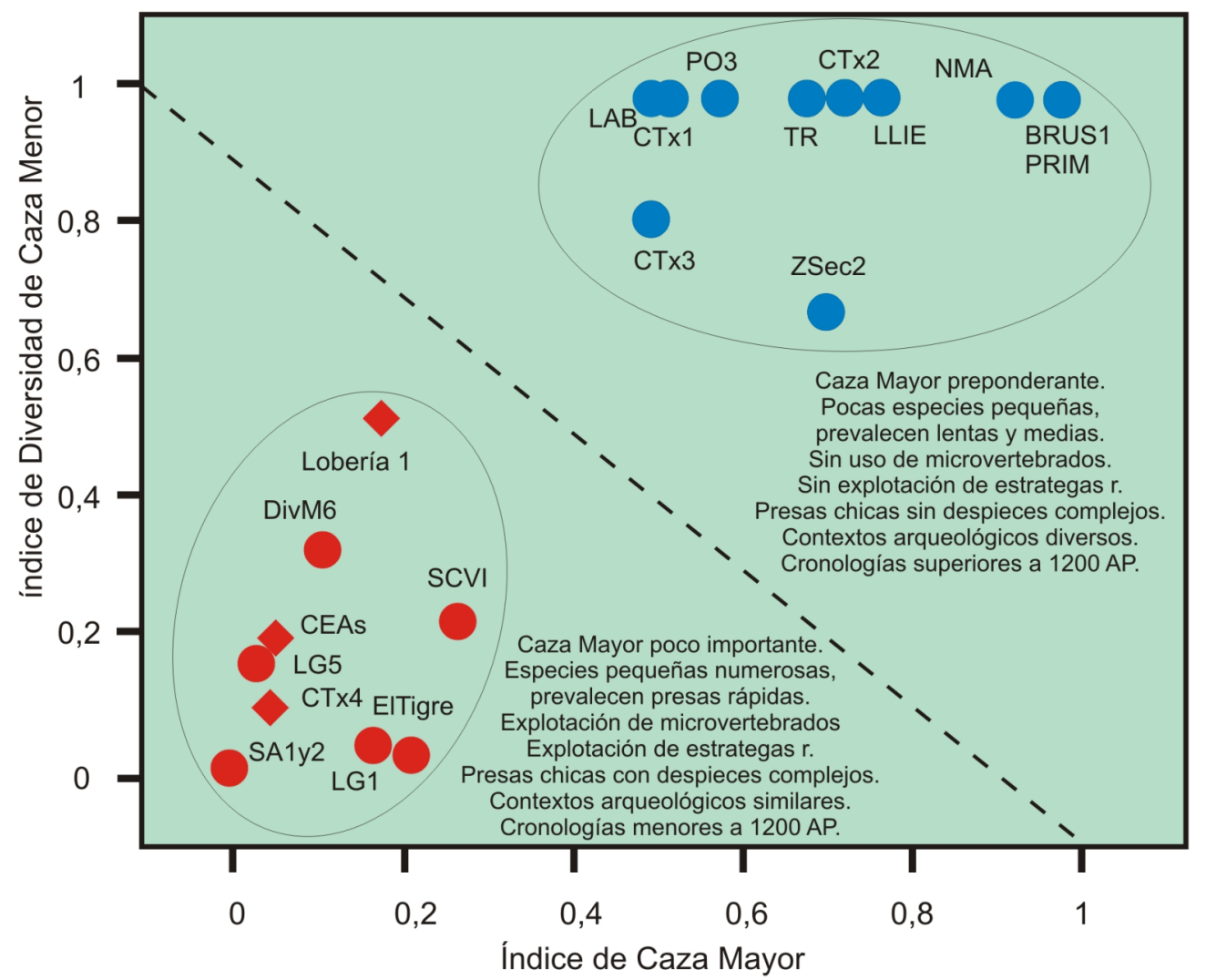

Figura 6. Indices combinados de Diversidad de Caza Menor y de Caza Mayor de ocupaciones arqueológicas de Tandilia comparadas con otras de la Región Pampeana y Norte de Patagonia.

CTx1: Cueva Tixi nivel arqueológico 1. CTx2: Cueva Tixi nivel arqueológico 2. CTx 3: Cueva Tixi nivel arqueológico 3. CTx 4: Cueva Tixi nivel arqueológico 4. CEAs: Cueva El Abra Componente superior. LOB I: Lobería I Ocupación superior. ELTigre: El Tigre (Martínez et al. 2005). 2 y 2: San Antonio 1 y 2 (Martínez et al. 2009). LG1: La Guillerma 1 (González 2005). LG5: La Guillerma 5 (González 2005). SCVI: San Clemente 6 (Paleo y Meroni 2004). TR: Laguna Tres Reyes Sitio 1 (Salemme y Madrid 2007). PO3: Paso Otero 3 (Martínez et al. 2001). NMA: Nutria Mansa (Bonomo 2005). ZSec2: Zanjón Seco 2 (Politis et al. 2001). LAB: Campo Laborde (Politis y Messineo 2008). LLIE: La Liebre (Pupio 1996). BRUS1: Las Brusquillas 1 (Massigoge 2012). PRIM: La Primavera (Martínez 2004). DivM6: El Divisadero Monte 6 (Aldazábal et al. 2007).

relacionadas con el predominio del ambiente fluvial, pero es destacable que al analizar la subsistencia a través de categorías se excluye la variable taxonómica y se reconoce el proceso de subsistencia involucrado obteniendo un panorama similar para ambas regiones, evidenciando la depreciación de la caza mayor y la diversidad de la caza menor (Figura 6). En esta cuenca la caza del coipo es dominante en la categoría intermedia, lo cual lo convierte en un recurso muy valorado en esta área, siendo una presa equivalente a la vizcacha en la economía de Tandilia Oriental: ambas especies son las presas de esa categoría más disponibles en cada área. Se destaca el procesamiento extenso del coipo en el Río Salado con evidencias de descarne, desarticulación, desollamiento y fracturas (González et al. 1997; González 2005; Escosteguy 2007a, 2007b; Escosteguy y Salemme 2012) lo cual es similar al aplicado en las 
vizcachas serranas (Quintana y Mazzanti 2011). Por su parte el bagre también presenta una explotación más profunda que en las sierras (González 2005) lo que podría cumplir un rol análogo a los roedores cávidos en Tandilia.

Más hacia el norte de la provincia de Buenos Aires, en la Localidad Arqueológica Barrio San Clemente, el sitio San Clemente VI se caracteriza por el uso simultáneo de fauna terrestre y marina (ca. 900 AP) (Paleo et al. 2002; Paleo y Meroni 2004; Day Pilaría et al. 2013). En ese contexto los ungulados fueron procesados exhaustivamente, tampoco son centrales en la economía y la fauna pequeña es diversa y numerosa. De este conjunto se incorporaron peces marinos, carpincho, vizcacha, coipo, armadillos y lagarto overo. Aunque no se cuenta con el análisis de los modos de procesamiento de las especies involucradas es significativo el uso abundante de especies pequeñas, el ocasional de los ungulados y la explotación acentuada de peces.

En el curso inferior del Río Colorado diversos sitios arqueológicos presentan una cronología asignable la Holoceno tardío final con registros de fauna explotada que contienen una estructura equivalente a la subsistencia descripta para Tandilia Oriental. Por ejemplo en el sitio El Tigre (ca. 900-500 AP) (Martínez et al. 2005; Martínez 2008-2009) el guanaco, el venado y el ñandú presentan MNI bajos. El guanaco se registró altamente fragmentado y con un conjunto diverso de fauna pequeña: aves, coipo y, mayormente, peces. En este sitio se destaca la incidencia en la captura de peces ribereños y el procesamiento intenso de las carcasas de ungulados (Stoessel 2014). Mientras que el sitio San Antonio 2 (ca. 800 $\mathrm{AP}$ ) también presenta una mayor preponderancia de la pesca, en este caso principalmente marina, y una menor incorporación de ungulados (Martínez et al. 2010). En esta área los análisis de numerosos artefactos de molienda permitieron plantear consumo de especies vegetales (Armentano 2004; Stoessel 2007). Nuevamente el panorama taxonómico es distinto respecto de Tandilia, pero es clara la similitud del proceso que definió la subsistencia en función de un uso profundo de la diversidad ambiental (uso de especies terrestres, fluviales, marinas y vegetales), de la explotación de especies pequeñas de distintas categorías y del procesamiento complejo de los ungulados y de algunas presas menores.

Los sitios del Holoceno tardío de Tandilia junto a los de la Depresión del Río Salado, de la Zona Norte de la provincia de Buenos Aires y del curso inferior del Río Colorado presentan un modo complejo de vinculación con el paisaje y denotan un esfuerzo exhaustivo en la apropiación de recursos. Los emergentes más conspicuos se manifiestan en el modo de explotación de la fauna de estos sitios, los cuales se distribuyen cronológicamente en un rango aproximado entre 500 y $1200 \mathrm{AP}$. Estas características, entre otras, llevaron a distintos autores a diferenciar arqueológicamente el Holoceno tardío inicial del Holoceno tardío final (Martínez 1999; Quintana y Mazzanti 2001; Stoessel 2007; entre otros).

Las diferencias de la subsistencia entre las áreas del Holoceno tardío final de la región Pampeana se definen por variables ambientales y se revelan por una mayor elección de especies terrestres en las sierras y en un aprovechamiento importante de los ambientes fluviales o marítimos en las otras microregiones que incorporan peces o aves de modo preponderante. Entre estas áreas, además, se manifiesta la diversidad en función de la importancia atribuida a cada especie según el ambiente en que se disponen los asentamientos, siendo la vizcacha, el coipo, el lagarto, los peces y las aves los organismos que presentan más disimilitud en la valorización como presa dentro y entre aéreas. 
En Tandilia oriental la subsistencia caracterizada por la intensificación y la diversificación tiene su registro más temprano alrededor de los 1000 AP. Integrando datos de otras áreas de la región, se verifica un descenso marcado en la incorporación de las presas más grandes entre los 1600 AP y los 1200 AP. Esto está acompañado simultáneamente por la caza más acentuada de especies menores de modo no aparente, es decir no es consecuencia de la disminución de la caza mayor (Figura 7).

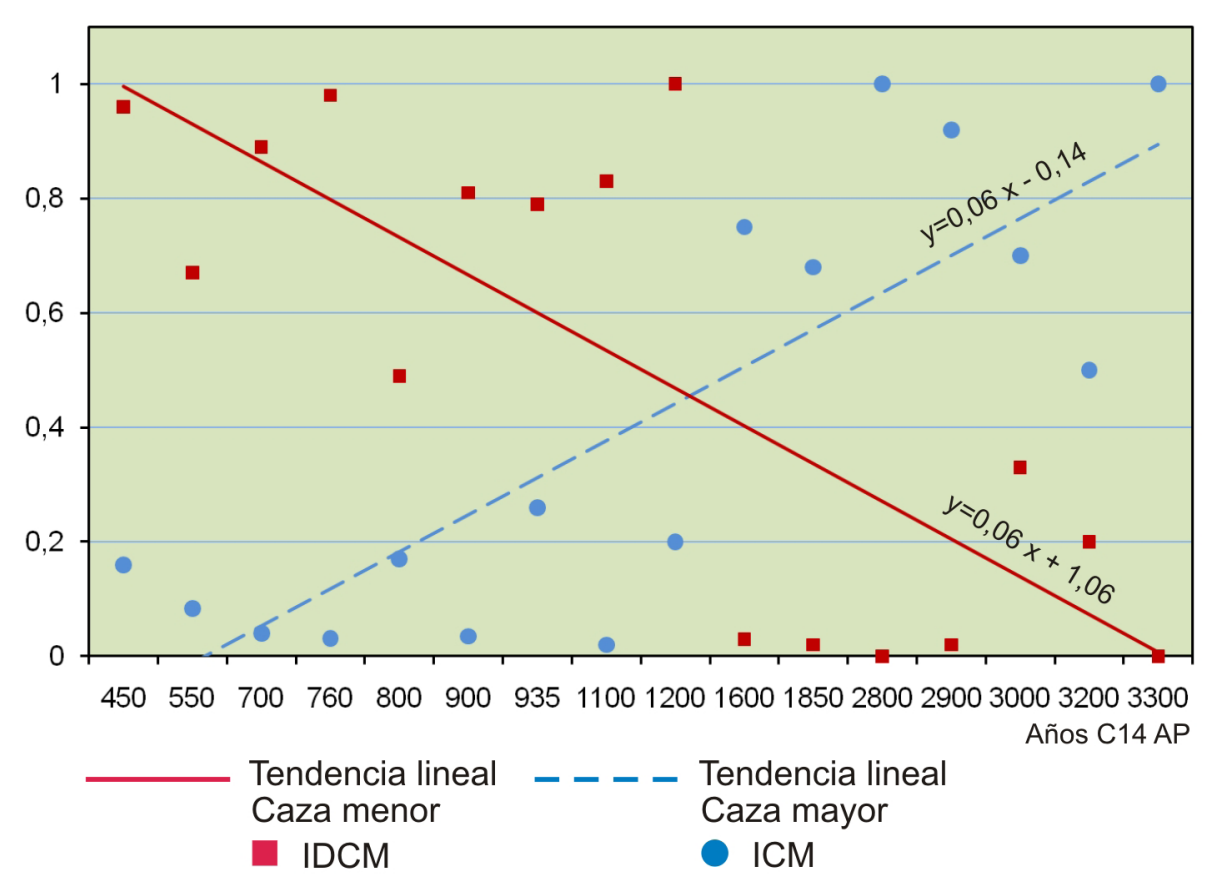

Figura 7. Índice de Diversidad de Caza Menor (IDCM) y de Caza Mayor (ICM) durante el Holoceno tardío de la región Pampeana y sus tendencias lineales a través del tiempo. Se cuantificaron los sitios: Cueva Tixi niveles arqueológicos 3 y 4, Cueva El Abra Componente superior, Lobería I Ocupación superior, El Tigre. San Antonio 2, La Guillerma 1 y 5, San Clemente 6, Laguna Tres Reyes 1, Nutria Mansa. Zanjón Seco 2, La Liebre, Las Brusquillas 1, La Primavera y Divisadero Monte 6 (referencias en la Figura 6). Debido a que el índice de Diversidad de Caza Menor manifiesta con valores absolutos más bajos al aumento de la caza menor, se graficó como 1 el valor de ese índice para facilitar la lectura de la figura.

En la figura 7 se cuantificaron algunos sitios arqueológicos de la región Pampeana a modo de referencia, donde se advierte el cambio conjunto entre la caza mayor y la caza menor, pero con tendencias absolutas opuestas. La tendencia lineal de pendiente negativa de la caza mayor denota la preponderancia progresiva de la cantidad de presas involucrada en la caza menor. A su vez, la pendiente positiva de la caza menor muestra la ampliación de la diversidad y de categorías de presas en relación con tiempos más tempranos.

Ese breve lapso entre los 1600 AP y los 1200 AP presenta menor cantidad de sitios arqueológicos y poca información zooarqueológica. Por ello todavía no es posible determinar la cronología más precisa del cambio, en qué área se inició ni cómo fue la coexistencia de ambos patrones, por lo que su dilucidación deberá ser resuelta a partir de nueva evidencia. 
La cronología tardía de la emergencia de la intensificación en Tandilia coincide con la etapa final del Óptimo Climático Medieval. Las secuencias sedimentarias de los sitios arqueológicos contienen evidencias de períodos de humedad indicadas por diatomeas que se desarrollan en suelos no encharcados, mientras que la fauna de vertebrados presenta especies de climas húmedos y cálidos (Mazzanti y Quintana 2012). Esta inferencia se corresponde con que, con posterioridad a estos niveles, se desarrollaron estratos que denotan cambios de las condiciones ambientales determinados por un evento más moderno y de mayor aridez (Pequeña Edad de Hielo) y que portan ocupaciones indígenas de otras características y estilos de subsistencia (Mazzanti 2007; Mazzanti y Quintana 2010a, 2010b).

\section{Un modelo de subsistencia para las sierras de Tandilia Oriental durante el Holoceno tardío final preconquista}

Como se expresó para el caso de Cueva Tixi (Quintana y Mazzanti 2001) durante el Holoceno tardío final se generó una situación que alteró el equilibrio que fue óptimo por varios milenios en Tandilia Oriental en el cual la caza especializada sobre poblaciones de ungulados sostenía lo principal de la subsistencia de las bandas cazadoras recolectoras. Este cambio generó un nuevo equilibrio, ocurrido junto al aumento de la densidad poblacional humana en el contexto de un comportamiento que acarreó menor movilidad de los grupos, mayor permanencia en los sitios, el desarrollo de tecnologías especializadas y de espacios ritualizados del paisaje lo cual también fue interpretado para otras áreas de la región durante el mismo lapso o tiempos inmediatamente anteriores (Martínez 1999; Martínez et al. 2005; Martínez y Gutiérrez 2004; González 2005).

En los tres sitios analizados la caza mayor comprendió a las tres especies grandes disponibles en el paisaje: guanaco, venado de las pampas y ñandú, pero los mamíferos fueron las presas principales por haber sido capturadas en mayor número y procesadas más profundamente, generando evidencias más abundantes y un aprovechamiento más extendido de las carcasas. La caza menor fue más diversa que en tiempos precedentes por incluir especies de mamíferos, reptiles, peces y aves. En síntesis, la caza menor de las tres cuevas denota un aprovechamiento de todas las especies mayores a 400 gramos disponibles en el paisaje. El conjunto explotado de Cueva El Abra y de Cueva Tixi son casi idénticos caracterizándose por la incidencia en la abundancia de la categoría rápida, en el aprovechamiento intenso de cuises, vizcachas y lagartos y en el consumo de peces. En Lobería I, las categorías media y lenta fueron proporcionalmente más importantes, careciendo del consumo de especies acuáticas.

Las dos clases de caza practicada por esas sociedades cazadoras-recolectoras presentan recurrencias que determinan un modelo y diferencias que informan acerca de la diversidad y discontinuidades intrínsecas de ese comportamiento. La disponibilidad geográfica y la estacionalidad de los recursos son las variables que orientaron la composición del conjunto explotado en el Holoceno tardío final de Tandilia, pero el tipo de subsistencia es lo que definió las propiedades de ese conjunto: la diversificación e intensificación es un proceso con características propias las cuales tienen diversidad en su expresión microregional e interregional.

La apropiación y aprovechamiento de recursos faunísticos durante el Holoceno tardío final de Tandilia oriental se corresponde con una estrategia de diversificación e intensificación de la subsistencia caracterizado por: 
1- disminución de la caza mayor respecto de otras estrategias de subsistencia y de ocupaciones más tempranas,

2- aprovechamiento exhaustivo de las carcasas de ungulados, con alta fragmentación y poca preservación de piezas enteras,

3- aumento de MNI\% de especies pequeñas de todas las categorías,

4- incorporación de recursos de reserva, especies que durante tiempos previos no fueron explotadas a pesar de estar disponibles en el ambiente: peces, lagartos, roedores cávidos y aves pequeñas,

5- captura de presas menores a un umbral de masa de $1 \mathrm{~kg}$ (microvertebrados),

6- incorporación de presas de fuga rápida,

7-desarrollo de procesamientos exhaustivos de la carcasa de algunas especies pequeñas (lagarto, roedores cávidos y vizcacha) que incluyeron todas las etapas del trozamiento, la fractura y el uso de la piel y de los huesos como fuente de matera prima.

Esta definición de la diversificación e intensificación en Tandilia Oriental representa un emergente local de esta estrategia de subsistencia, por lo que algunos de estos rasgos son compartidos con otras áreas de la región Pampeana. Sin embargo la extensión de estos atributos permite caracterizar este fenómeno de modo local y acotado a esta microrregión.

Agradecimientos: A los editores Matías Medina y Luciano Prates por su invitación a participar de este volumen. A numerosos autores que tuvieron la gentileza de compartir datos inéditos o de reciente publicación y que contestaron reiteradas consultas, entre ellos Gustavo Martínez, Paula Escosteguy, Matías Medina, María Isabel González, Fernanda Day Pilaría, María Clara Paleo y Agustina Massigoge. Este artículo forma parte de proyectos aprobados y financiados por la Universidad Nacional de Mar del Plata y por la Agencia Nacional de Promoción Científica y Tecnológica PICTO 552.

\section{Bibliografía citada}

Aldazabal, V.; M. Silveira y E. Eugenio 2007 Zooarqueología del sitio "El Divisadero Monte 6" Tras las huellas de la materialidad. XVI CNAA, 3: 241-246. Jujuy, Editorial de la Universidad de Jujuy.

Armentano, G.

2004 Organización de la Tecnología Lítica en el valle inferior del río Colorado (Pdos. de Patagones y Villarino, Pcia. de Buenos Aires). Tesis de Licenciatura. Facultad de Ciencias Sociales, UNCPBA, Olavarría.

Bonomo, $\mathrm{M}$.

2005. Costeando las llanuras. Arqueología del litoral marítimo pampeano. Sociedad Argentina de Antropología, colección tesis doctorales. 
Branch L.

1993. Seasonal patterns of activity and body mass in the plains vizcacha, Lagostomus maximus (family Chinchillidae). Canadian Journal of Zoology 71:1041-1045.

Day Pilaría F.A., M.L. Merino y R.C. Gambaro

2013 Explotación y consumo de cérvidos en el litoral fluvial bonaerense durante el Holoceno tardío final: análisis de los sitios San Clemente VI y Las Marías. Rev. Museo La Plata, Sección Antropología 13 (87):153-166.

Duarte Varela, C. y M. Cabrera

2000 Testing skeletochronology in black tegu lizards (Tupinambis merianae) of known ages. Herpetological Review 31 (4):224-226.

Escosteguy, P.

2007a Estudios sobre restos de Myocastor coypus en sitios de la cuenca inferior del Río Salado. Arqueología en las Pampas (Bayón C., A. Pupio, I. y M. Frère eds.). 1:471-487. EDIUNS, Departamento de Humanidades, Universidad Nacional del Sur.

Escosteguy, P.

2007b Los roedores en la localidad arqueológica La Guillerma y los sitios San Ramón 7 y Río Luján. La Zaranda de Ideas. Revista de Jóvenes Investigadores en Arqueología 3:21-39.

Escosteguy, P. y M. Salemme

2012 Butchery evidence on rodent bones from archaeological sites in the Pampean Region (Argentina). Proceedings of the General Session of the 11th International Council for Archaeozoology Conference (C. Lefèvre Ed.). pp:227-236. BAR International Series 2354.

Frontini, R.

2013 Aprovechamiento faunístico en entornos acuáticos del sudoeste bonaerense durante el Holoceno (6900-700 años AP). Relaciones 38 (2):493-519.

González, M.

1994 Potsherds, 'coypo' teeth, and fish bones: Hunter-gatherer-fishers in the Río Salado (Pampa Region, Argentina). Quaternary of South America and Antarctic Peninsula 10:255-279.

González, M.

2005 Arqueología de alfareros, cazadores y pescadores pampeanos. Sociedad Argentina de Antropología. Colección Tesis Doctorales.

González M., M. Salemme y M. Frere

1997 El coipo o "nutria" (Myocastor coypus bonariensis) como recurso en la economía de cazadores recolectores pampeanos. Arqueología pampeana en la década de los '90 (Berón M. y G. Politis Eds.). Pp:201-212. Museo de Historia Natural de San Rafael, Mendoza. XI Congreso Nacional de Arqueología Argentina. INCUAPA UNICEN.

Gutiérrez, M.A, G. Martínez, M.S. Bargo y S. Vizcaino

2010Supervivencia diferencial de megafauna en la región pampeana en el Holoceno temprano y su relación con aspectos paleobiológicos. Zooarqueología a principios del siglo XXI: aportes teóricos, metodológicos y casos de estudio. (M. Gutiérrez, M. De Nigris, P.M. Fernández, M. Giardina, A.F. Gil, A. Izeta, G. Neme y H.D. Yacobaccio, Eds.) pp. 231-241. Ediciones del Espinillo 
Mansur, E., Lasa A. y Mazzanti D.

2009 El uso de sustancias colorantes en el tratamiento de pieles. Arqueometría Latinoamericana, 2do. Congreso Argentino, 1ro. Latinoamericano 1:142-150.

Martínez, G.

1999 Tecnología, subsistencia y asentamiento en el curso medio del Río Quequén Grande: un enfoque arqueológico. Tesis doctoral, Biblioteca de la Universidad Nacional de La Plata.

Martínez, G.

2004 Resultados Preliminares de las investigaciones arqueológicas realizadas en el curso inferior del río Colorado (Pdos. de Villarino y Patagones). Aproximaciones Contemporáneas a la Arqueología Pampeana. (Martínez, G.; Gutierrez, M.; Curtoni, R.; Berón, M. y P. Madrid Eds.) pp. 275-292. Publicación de la Facultad de Ciencias Sociales. UNCPBA.

Martínez, G.

2008-2009 Arqueología del curso inferior del río colorado: estado actual del conocimiento e implicaciones para la dinámica poblacional de cazadores-recolectores pampeanopatagónicos. Cazadores recolectores del cono sur. Revista de arqueología 3: 71-92.

Martínez, G. A., P.G. Messineo, M.E. Piñeyro, C.A. Kaufmann y M.P. Barros 2001 Análisis preliminar de la estructura faunística del sitio Paso Otero 3 (Pdo. de Necochea, Pcia. de Bs. As., Argentina). Arqueología Uruguaya Hacia el Fin del Milenio, 1:505-520.

Martínez, G. y M. Gutiérrez

2004 Tendencias en la explotación humana de la fauna durante el Pleistoceno final y Holoceno en la Región Pampeana (Argentina). Zooarchaeology of South America, (Mengoni Goñalons G. Ed.). pp:81-98. BAR Internacional Series 1298.

Martínez, G., F. Zangrando, L. Stoessel

2005 Sitio El Tigre (pdo. de Patagones, pcia. de Buenos Aires, Argentina): evidencias sobre la explotación de peces en el curso inferior del Río Colorado e implicaciones para los sistemas de subsistencia. Magallania 33 (2):99-114.

Martínez, G., G. Armentano, L. Stoessel, G.A. Martínez, A.P. Alcaraz, N. González y F. Santos 2010 Resultados Preliminares de la localidad arqueológica San Antonio (curso inferior del río Colorado Pdo. Villarino, Pcia. de Buenos Aires). Mamül Mapu: pasado y presente desde la arqueología pampeana, ( M. Berón, L. Luna, M. Bonomo, C. Montalvo, C. Aranda y M. Carrera Aizpitarte Eds.). pp:241-252. Editorial Libros del Espinillo.

Massigoge, A.

2012 Las Brusquillas 1 (partido de San Cayetano, provincia de Buenos Aires): un nuevo sitio del Holoceno tardío del área Interserrana de la región pampeana. Intersecciones en Antropología 13 (2): 377-392.

Mazzanti, D.

2005. Indicadores de cambio económico-social en las sierras de Tandilia durante el Holoceno Tardío. IV Congreso de Arqueología de la Región Pampeana Argentina, Libro de Resúmenes pp. 46-47. Bahía Blanca. 
Mazzanti, D.

2006 La constitución de territorios sociales durante el Holoceno tardío. El caso de las sierras de Tandilia. Argentina Relaciones 31: 277-300.

Mazzanti, D.

2007 Arqueología de las relaciones interétnicas posconquista en las sierras de Tandilia. Tesis doctoral Facultad de Filosofía y Letras, UBA.

Mazzanti, D. y V. Puente

2014 La producción textil como actividad doméstica de los cazadores-recolectores prehispánicos en la región pampeana, Argentina. Intersecciones en Antropología 16. En prensa

Mazzanti, D. y J. Porto López

2007 Caracterización petrográfica y estructural de cerámicas arqueológicas de las sierras de Tandilia. Cerámicas arqueológicas. Perspectivas arqueométricas para su análisis e interpretación (M.B. Cremonte y N. Ratto Eds.). pp. 97-122. Editorial Universidad Nacional de Jujuy, San Salvador de Jujuy.

Mazzanti, D. y F. Valverde

2001 Artefactos sobre hueso, asta y valva. Cueva Tixi: Cazadores y Recolectores de las Sierras de Tandilia. I. Geología, Paleontología y Zooarqueología (D. Mazzanti y C. Quintana Eds). pp: 157-180. Publicación Especial 1. LARBO-UNMDP.

Mazzanti, D. y Quintana C.

2010a Estrategias de subsistencia de las jefaturas indígenas del siglo XVIII. Zooarqueología de la Localidad Arqueológica Amalia (Tandilia Oriental). Relaciones 25:143-170.

Mazzanti, D. y Quintana C.

2010b Fauna y ambiente en la subsistencia indígena durante el Siglo XVIII en Tandilia Oriental. Anuario IEHS 27: 209-221.

Mazzanti D., M. Colobig, A. Zucol, G. Martínez, J. Porto López, M. Brea, E. Passegi, J. Soria, C. Quintana y V. Puente

2010 Investigaciones Arqueológicas en el sitio 1 de la Localidad Lobería I. Mamül Mapu: pasado y presente desde la arqueología pampeana. (M. Berón, L. Luna, M. Bonomo, C. Montalvo, C. Aranda y M. Carrera Aizpitarte) 2:99-114. Editorial Libros del Espinillo.

Medina, M., D. Rivero y P. Teta

2011 Consumo antrópico de pequeños mamíferos en el Holoceno de Argentina central: perspectivas desde el abrigo rocoso Quebrada del Real 1 (pampa de Achala, Córdoba) Latin American Antiquity 22 (4):618-631.

Messineo, P.G. y G. Politis

2009 New Radiocarbon Dates from the Campo Laborde Site (Pampean Region, Argentina) Support the Holocene Survival of Giant Ground Sloth and Glyptodonts. 2009. Current Research in the Pleistocene 26:5-9. 
Outram, A.

2001 A New Approach to Identifying Bone Marrow and Grease Exploitation: Why the "Indeterminate" Fragments should not be ignored. Journal of Archaeological Science 28: 401-410.

Paleo M., Páez M. y Meroni M.

2002 Condiciones ambientales y ocupación humana durante el holoceno tardío en el litoral fluvial bonaerense. Del Mar a los Salitrales. Diez mil años de ocupación humana en los umbrales del tercer milenio. (Mazzanti D., Berón, M. y F. Oliva eds.). pp:365-377. Universidad Nacional de Mar del Plata, Sociedad Argentina de Antropología.

Paleo, M. y Meroni M.

2004 Problemáticas vinculadas a las estrategias de subsistencia de la Localidad Arqueológica Barrio San Clemente. La Región Pampeana, su pasado Arqueológico. (Gradín C. y Oliva F. Eds.). Pp:311-319.

Politis, G.

1984 Investigaciones arqueológicas en el Área Interserrana Bonaerense. Etnía 32:7-52.

Politis, G., G. Martínez, M. Bonomo

2001 Alfarería temprana en sitios de cazadores recolectores de la Región Pampeana (Argentina). Latin American Antiquity 12 (2):167-181.

Politis, G. y P.G. Messineo

2008 The Campo Laborde site: new evidence for the Holocene survival of Pleistocene megafauna in the Argentine Pampas. Quaternary International 191:98-114.

Porto López, J.M. y D. Mazzanti

2009 Pigmentos minerales arqueológicos y fuentes de aprovisionamiento del sudeste bonaerense: Análisis arqueométrico comparativo. Arqueometría Latinoamericana, 2do. Congreso Argentino, 1ro. Latinoamericano, 1: 215-220.

Pupio, A.

1996 Resultados preliminares del sitio cantera-taller La Liebre. Jornadas Chivilcoyanas en Ciencias Sociales y Naturales, pp. 191-194.

Quintana, C.

2015 Patrón esqueletario de roedores cávidos en la secuencia arqueológica de Cueva Tixi, Tandilia Oriental (Pleistoceno tardío - Holoceno tardío). Archaeofauna 24. En prensa

Quintana, C.

2005 Despiece de micro roedores en el Holoceno Tardío de las sierras de Tandilia, Argentina. Archaeofauna 217:227-241,

Quintana, C.

2008 Cálculo del número mínimo de individuos de huevos de ñandú. Intersecciones en Antropología, 9:17-21. 
Quintana, C. y D. Mazzanti

2001. Selección y aprovechamiento de recursos faunísticos. Cueva Tixi: Cazadores y Recolectores de las Sierras de Tandilia. I. Geología, Paleontología y Zooarqueología (D. Mazzanti y C. Quintana Eds). pp:181-209. Publicación Especial 1. LARBO-UNMDP.

Quintana, C. y D. Mazzanti

2010 Caza menor en sitios arqueológicos de Tandilia Oriental. Zooarqueología a principios del siglo XXI. Aportes teóricos, metodológicos y casos de estudio. (Gutiérrez M., De Nigris M., Fernández P., Giardina M., Gil A., Izeta A., Neme G. y H Yacobaccio Eds.) Pp:307-319. Ediciones del Espinillo.

Quintana, C. y D. Mazzanti

2011 Las vizcachas pampeanas (Lagostomus maximus, Rodentia) en la subsistencia indígena del Holoceno tardío de las sierras de Tandilia oriental (Argentina). Latin American Antiquity 22(2):253-270.

Quintana, C., F. Valverde y D. Mazzanti

2002 Roedores y lagartos como emergentes de la diversificación de la subsistencia durante el Holoceno de las sierras de Tandilia, Argentina. Latin American Antiquity. 13 (4):455-473.

Quintana C., F. Valverde y A. Albino

2003 Registro de fauna del sitio Cueva El Abra, Tandilia Oriental, Provincia de Buenos Aires. Actas XIII Congreso Nacional de Arqueología Argentina 3:317-324.

Salemme, M. y P. Madrid

2007 The archaeofaunas from Laguna Tres Reyes 1 site: taxonomic richness and abundance during the beginning of the Late Holocene in the south-east Pampean Region (Argentina). Taphonomy and Zooarchaeology in Argentina. (Gutiérrez, M.; Miotti, L.; Barrientos, G.; Mengoni Goñalons, G. y Salemme, M. Eds.). pp: 121-143. B.A.R. (International Series) 1601. Archaeopress, Oxford.

Salemme, M., P. Escosteguy y R. Frontini

2012 La fauna de porte menor en sitios arqueológicos de la región pampeana, Argentina. Agente disturbador vs. recurso económico. Archaeofauna 21: 163-185

Stoessel, L.

2007 Análisis arqueofaunisticos de los sitios Loma Ruiz 1 y El Tigre (partidos de Villarino y Patagones, provincia de Buenos Aires). Aportes para el conocimiento de la subsistencia en el valle inferior del río Colorado durante el Holoceno tardío. Intersecciones en antropología 8:235-251.

Stoessel, L.

2014. Evaluating Intensity in the Processing of Guanaco (Lama guanicoe) at the Lower Basin of the Colorado River (Argentina): Fragmentation Levels and Fracture Patterns Analysis. International Journal of Osteoarchaeology 24:51-67.

Zucol, A., M. Brea y D. Mazzanti

2005 Prospección y análisis de restos orgánicos presentes en cerámicas de las sierras de Tandilia (Provincia de Buenos Aires), $3^{\circ}$ EIF. The Phytolitharien, 17(2): 14-15. . 